\title{
RESPONSIBLE GAMBLING SIGNAGE ON ELECTRONIC GAMING MACHINES, BEFORE AND AFTER THE IMPLEMENTATION OF THE UNITED KINGDOM (UK) GAMBLING ACT: AN OBSERVATIONAL STUDY.
}

\author{
CRAWFORD MOODIE ${ }^{1}$ and GERDA REITH ${ }^{2}$ \\ ${ }^{1}$ Institute of Social Marketing, University of Stirling, Scotland; ${ }^{2}$ Department of \\ Sociology, Anthropology and Applied Social Sciences, University of Glasgow, \\ Scotland
}

\begin{abstract}
The 2005 Gambling Act in Britain requires all gambling operators to satisfy responsibility codes as a condition of licence, such as signage on electronic machines, and in the venues in which they are located, encouraging responsible gambling and signposting help available. This observational study found that eighteen months prior to the implementation of the Act, only 4.1\% of the 1,351 electronic machines located in Glasgow City Centre displayed signs promoting responsible gambling and signposting the national Gamcare helpline. One month after the introduction of the Act, which stipulated that all machines must display such signage, this was only evident on 65\% of machines. Other responsible gambling signage (posters, signs, leaflets, brochures) was not highly visible in either phase. These findings highlight two important points; first, most sectors of the gambling industry are not embracing the new social responsibility codes (or indeed even adhering to them); and, second, if licensing conditions are not made explicit, as is the case in Britain, the gambling industry can dictate what is meant by 'responsible' and so define what measures are sufficient to meet this criteria.
\end{abstract}

\section{Introduction}

Liberalisation of the UK gambling market

The full implementation of the Gambling Act (2005) in September 2007 creates the conditions for the liberalisation, and ultimately normalisation, of gambling to an extent never previously witnessed in Britain. The Act expands the existing regulatory framework to cover all forms of commercial gambling, and sees a move from the restrictive gambling policy in place for the previous four decades. The decision to relax the gambling market is the combined result of greater public tolerance towards gambling, rapid technological advancement and the need for a new licensing regime based on commercial interests (Gambling Review Body, 2001). The latter, and particularly the symbiotic association between government revenue and commercial profit, has certainly provided the thrust for the liberalisation of gambling in many countries (Reith, 2007). Britain appears to have followed suit, with the government accused of being "driven by a commercial imperative masquerading as a desire to allow greater freedom for the sensible majority” (Light, 2007, p. 644). Prior to the Act gambling was already socially and culturally accepted in Britain. The lifting of restrictions on gambling advertising in conventional and digital media, allied to the expected proliferation of gambling opportunities, is likely to further foster this acceptance of gambling.

The liberalisation of gambling markets is often accompanied by increased rates of problem gambling, although the relationship is not straightforward, and is influenced by an array of mediating factors (Abbott, 2006). Some mediating factors 
can mitigate increases in problem gambling, for example the availability of treatment and strong regulatory controls, whereas others, such as increases in continuous forms of gambling, facilitate rises in problem gambling, On this basis the outlook for Britain is not promising given the startling dearth of treatment facilities for problem gambling (Orford, 2005; British Medical Association, 2007; Moodie, 2008) and the fact that the Gambling Act paves the way for an increase in continuous forms of gambling, such as betting shops and electronic gaming machines (EGMs) in casinos (Light, 2007). This could represent a significant problem given that the extant global literature has firmly established the association between problem and pathological gambling and EGM use, either exclusively or jointly, in both adolescents and adults (e.g. Moodie and Finnigan, 2006; MORI/IGRU, 2006; Hodgins and el-Guebaly, 2004; Götestam and Johansson, 2003; Cox et al., 2004; MacCallum and Blaszczynski, 2003; Pietrzak and Petry, 2005). The insidious nature of EGMs appears to be the consequence of a combination of structural (e.g. high event frequency) and situational (e.g. high availability) characteristics. Both these factors enhance the addiction potential of EGMs (Williams et al., 2007).

It has been suggested that another mediating factor will be the regulatory controls implemented by the Gambling Commission, i.e. the operating license conditions and codes of practice, which will ultimately determine the success of the Gambling Act (Light, 2007) and future levels of problem gambling.

\section{Social responsibility codes of practice}

The Licence Conditions and Codes of Practice (LCCP), published in June 2007 by the Gambling Commission, stipulates that, as a condition of licence, gambling operators are required to adhere to social responsibility codes of practice. Essentially, the philosophy underlying these codes is the prevention of gambling related harms through a commitment to responsible practices on the part of government, operators and, in particular, players themselves. At its core it rests on the assumption that the provision of information on such issues as the risks of excessive play, as well as how and where to access help and treatment, through strategies such as signage in venues and on machines, will encourage informed choice and, through this, responsible play on the part of individual gamblers. Whether or not this emphasis on social responsibility will be enough to stabilise, or even reverse, rates of problem gambling will only become evident in time (Miers, 2007). A more immediate issue is the extent to which gambling operators are willing to adopt the social responsibility measures outlined in the LCCP. To examine this we assess what visible measures gambling operators have taken to meet the main 'Responsible gambling and help' code on the LCCP and also the 'Machine standards' code, a supplementary code published at the same time (Gambling Commission, 2007a; Gambling Commission, 2007b).

The Machine standards code requires all gaming machine operators to prominently display information signposting available help, via the national GamCare helpline number (Department for Culture, Media and Sport, 2007; Gambling Commission, 2007b). The Responsible gambling and help code stipulates that all licensees must ensure that information is readily available on how to gamble responsibly and how to access information about both problem gambling and available help. Licensees must take 'all reasonable steps' to ensure that this information is prominently displayed, appropriate to the size of the premises and readily accessible near EGMs, ATMs, in the main gambling area, and also in locations where it can be obtained discreetly (near exit doors or in toilets). The LCCP further states that 'where relevant' information must cover the availability of 
measures that are accessible to help an individual monitor or control their gambling, such as limiting the duration of the gambling session and expenditure, and also selfexclusion.

Prior to the LCCP, the Association of British Bookmakers formed a voluntary agreement with Gamcare in 2003 to implement the Good Practice and Social Responsibility Code (GPSRC) for betting offices. Inclusive in the GPSRC, which came into effect in 2004, was the restriction of the number of EGMs in any one betting shop to four and increasing patrons' awareness of help and responsible gambling via prominent notices, posters and leaflets. With the introduction of the Act, the code is no longer voluntary, but under the purview of the Gambling Commission. However, no research has examined what efforts to encourage responsible gambling and increase awareness of problem gambling and help available betting shops have actually put in to place, and what measures other gambling venues have incorporated.

In the present study, the centre of Scotland's largest and most populated city (Glasgow) was selected in order to examine signage on EGMs and in the venues in which they are located prior to, and following, the implementation of the Gambling Act. This allows assessment of gambling providers' compliance with the LCCP, and the degree to which the 'responsible gambling' message appears to have been adopted by gambling operators.

\section{Methods}

\section{Design and Procedure}

Given that the purpose of the present study was to assess gambling operators' compliance with the new responsibility codes, two methods were considered. The first was interviews with managers or owners of gambling venues, pre-Act, to investigate their views on responsible gambling and what measures they intended to implement, followed by observational research, post-Act, examining what measures each gambling venue had actually implemented. The second method considered was observational research, both prior to and after the Act, allowing a first-hand look at the measures that were in place before the Act and what changes were made after it. The latter was selected given potential difficulties accessing owners or managers of gambling venues, and because observational research offers an accurate picture of the visible measures gambling operators had introduced.

Ethical approval was obtained from the Ethics Committee at Glasgow Caledonian University (CM's institution at study onset). Approval was not sought from gambling providers, however, for four reasons; first, there was no human involvement; second, the nature of the research involved covertly examining industry response to responsible gambling measures and disclosing this information to gambling operators in advance would have undermined the purpose of the research; third, it would have been extremely time-consuming and resulted in high refusal rates (particularly from those operators not following legislation), giving an inaccurate, and unhelpful, picture of what is happening in the UK; fourth, the marketing literature is replete with consumer research where operator consent is not required (whether within shops, pubs, etc).

For venues to be included in the study they had to be located within the boundaries of Glasgow City Centre, and contain an EGM. It may appear, at first, that the requirement of a venue to have an EGM to be included in the study is restrictive, however, every venue offering gambling facilities within the centre of Glasgow has at least one EGM (except for retailers who sell lottery tickets and scratchcards). We chose to exclude retailers selling lottery tickets and scratchcards and focus exclusively 
on forms of gambling, such as machine gambling, that can only be played in situ, in keeping with previous observational research (Gambling Research Australia, 2007).

The study consisted of two Phases; the first eighteen months prior to the Act, the second one month after the Act. The procedure was the same for each phase and involved visiting every possible venue within the boundaries of Glasgow City Centre which might contain an EGM (within a two week period). There were four casinos, eleven amusement arcades, twenty-seven betting shops and at least one hundred and fifty-one ambient venues (pubs, nightclubs, hotel and restaurants, i.e. venues where gambling is ancillary to the main purpose of the business) within Glasgow City Centre containing EGMs at Phase 1. At Phase 2, there were a similar number of venues, with two additional bookmakers and one additional arcade.

The number and types of machines in these venues were catalogued (counted manually by CM, and double checked) and each machine, and each venue, meticulously examined for signage promoting responsible gambling. A structured monitoring tool, based on existing responsible gambling measures in place at the time of the first phase of the study, was employed to ensure accuracy of observations. The single-page instrument allowed the observer (always CM, at both phases) to detail information concerning; the type of venue; the number, and types of EGMs, found in each venue; the presence of signage on EGMs; the presence of signs, posters, leaflets and brochures in each venue (including number of each and location).

\section{Results}

\section{Number and types of EGM'S}

There were (at least) 1,351 electronic gaming machines in Glasgow City Centre at Phase 1; 972 in amusement arcades, 109 in betting shops, 104 in casinos, and 166 in ambient venues. This number had decreased slightly at Phase 2 to 1,251 . We are confident that all main gambling venues (arcades, betting shops and casinos), and all EGMs within these venues, were identified at both phases. It is possible however that ambient venues may not have been identified at either phase and, as such, we may have failed to capture all EGMs in these venues. Table 1 displays the types of EGMs in different venues, with Category $\mathrm{D}$ and Category $\mathrm{C}$ fruit machines the only machines legally available in ambient venues. Category B2 machines predominate in bookmakers, with Category B1, B3 and B4 machines in casinos. Amusement arcades typically have a combination of Category D, C, B3 and B4 machines. The Gambling Act stipulated that only four Category B3 and B4 machines be available for use at any one time within an arcade.

Table 1. Types of EGM found in the UK

\begin{tabular}{|l|c|c|c|c|}
\hline \multicolumn{1}{|c|}{ Type } & Description & Location & $\begin{array}{c}\text { Maximum } \\
\text { Stake (£) }\end{array}$ & $\begin{array}{c}\text { Maximum } \\
\text { Prize (£) }\end{array}$ \\
\hline Category B1 & High-intensity & Casinos & 2 & 4000 \\
\hline Category B2 & FOBTs * & Bookmakers & 100 & 500 \\
\hline Category B3 & Low-intensity & $\begin{array}{c}\text { Arcades, } \\
\text { bookmakers, } \\
\text { casinos }\end{array}$ & 1 (2 pre-Act) & 500 \\
\hline Category B4 & Low-intensity & Arcades, casinos & 1 (2 pre-Act) & 250 \\
\hline Category C & Fruit machines & $\begin{array}{c}\text { Ambient venues, } \\
\text { arcades, } \\
\text { bookmakers }\end{array}$ & 0.5 & 35 \\
\hline
\end{tabular}




\begin{tabular}{|l|l|c|c|c|}
\hline Category D & Fruit machines & $\begin{array}{c}\text { Ambient venues, } \\
\text { arcades }\end{array}$ & 0.3 & $\begin{array}{c}5 \\
\text { (£8 tokens) }\end{array}$ \\
\hline
\end{tabular}

* FOBTs are Fixed-Odds Betting Terminals, which allow betting on the outcome of various games and events with fixed odds

Responsible gambling signage (stickers) on machines

In terms of promoting responsible gambling and signposting help available, only $4.1 \%(\mathrm{~N}=55)$ of all EGMs were found to display such information at Phase 1 . No responsible gambling stickers were evident within any ambient venue, being most prominent on machines in betting shops ( $\mathrm{N}=10, \mathrm{M}=9.6 \%)$. Casinos tended to have signage on a small proportion of machines $(\mathrm{N}=5, \mathrm{M}=4.8 \%)$ and amusement arcades an even smaller proportion ( $\mathrm{N}=40, \mathrm{M}=4.1 \%)$. At Phase 2, 65\% of all EGMs ( $\mathrm{N}=$ 818) displayed responsible gambling signage, evident for the first time on EGMs in ambient venues and increasing in all other venues (see Table 2). Every EGM in betting shops had stickers, although this was not the case for casinos $(\mathrm{N}=101, \mathrm{M}=$ 91.0\%) and arcades ( $\mathrm{N}=469, \mathrm{M}=53.2 \%)$. In fact, even though all arcades and casinos had signage on some EGMs at Phase 2, none had signage on all EGMs. Therefore, no arcade or casino was able to fully comply with the Machine standards code. In addition, the size of the actual stickers was generally quite small in most gambling venues (approximately two square inches), and extremely small in others (approximately one square inch). As such, the wording on stickers was sometimes difficult to read.

Table 2. Types and numbers of electronic gaming machines in Glasgow City Centre before, and after, the introduction of the Gambling Act, and number of machines with responsible gambling signage (in bold)

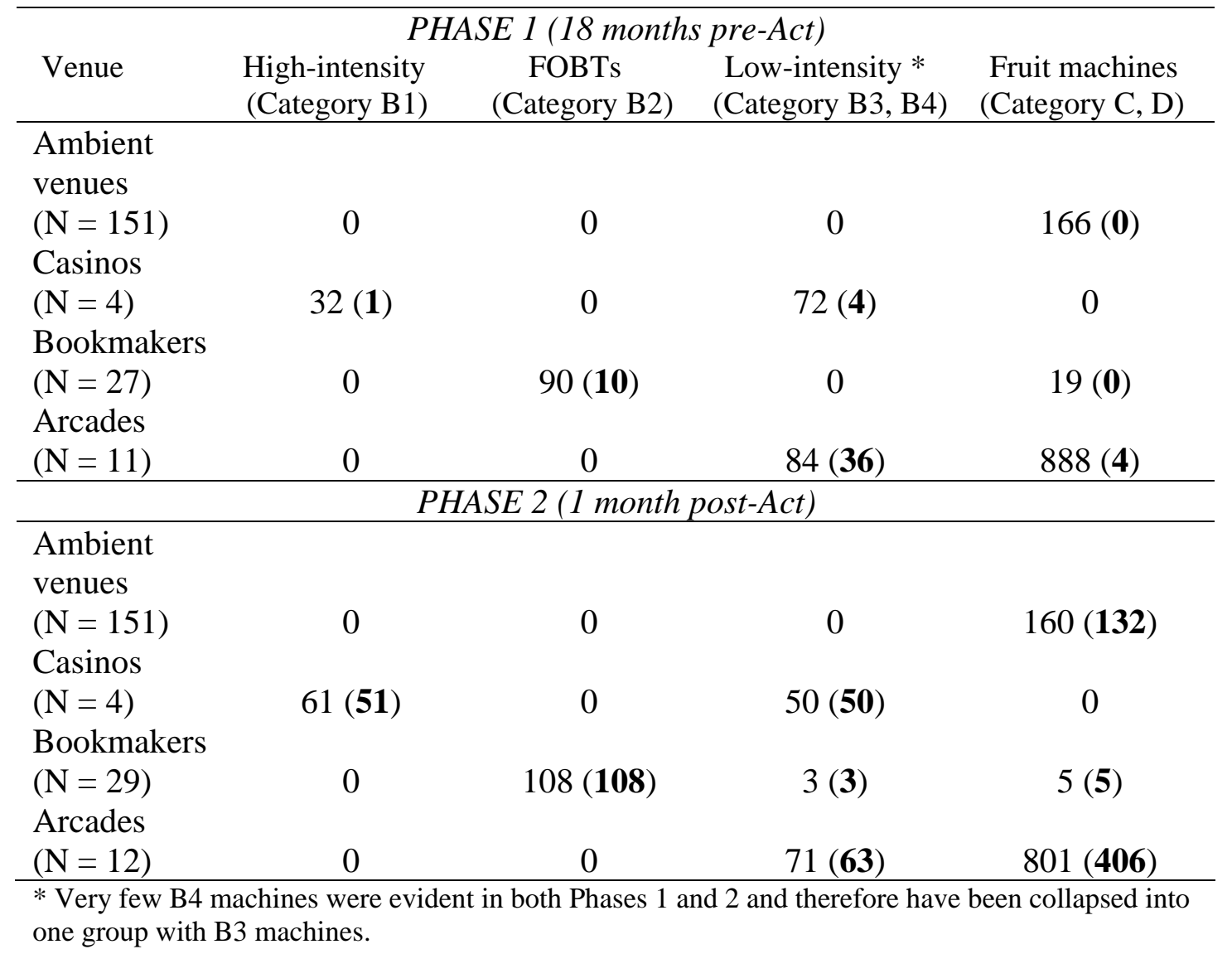


Responsible gambling signage (posters and leaflets) in venues in which machines are located

In the first phase no responsible gambling signage (in the form of signs, posters, leaflets or brochures) was evident in either amusement arcades or ambient venues. Except from one arcade, displaying a single poster, located near the exit and with leaflets highlighting the dangers of problem gambling attached, no other arcade or ambient venue displayed responsible gambling signage at Phase 2. Signage in all casinos was evident both before and after the introduction of the Act, generally located on ATMs, change machines, in discreet locations (toilets and near exits) but absent in the main gambling area and next to EGMs (see Table 3). At Phase 1, 75\% of casinos had leaflets and signs, with this increasing to $100 \%$ at Phase 2. For bookmakers, 96\% had leaflets and 22\% signs at Phase 1, with all bookmakers having leaflets at Phase 2, with 28\% having signs.

Table 3. Location of responsible gambling signage in bookmakers and casinos across the two phases

\begin{tabular}{lcccc}
\hline & \multicolumn{2}{c}{ Bookmakers } & \multicolumn{2}{c}{ Casinos } \\
& $\begin{array}{l}\text { Phase } 1 \\
(\mathrm{~N}=27)\end{array}$ & $\begin{array}{c}\text { Phase 2 } \\
(\mathrm{N}=29)\end{array}$ & $\begin{array}{c}\text { Phase } \\
(\mathrm{N}=4)\end{array}$ & $\begin{array}{c}\text { Phase 2 } \\
(\mathrm{N}=4)\end{array}$ \\
\hline $\begin{array}{l}\text { Average number of leaflets } \\
\text { or brochures per venue }\end{array}$ & 2.71 & 2.80 & 1.00 & 1.25 \\
Where & & & & \\
Next to EGMs & 2.00 & 2.00 & 0 & 0 \\
Main gambling area & 0.15 & 0.11 & 0 & 0 \\
On ATMs * & N/A & N/A & 0 & 0 \\
At change machine/desk * & N/A & N/A & 0.25 & 0.25 \\
Toilets & 0 & 0 & 0.25 & 0.50 \\
Exits & 0.56 & 0.69 & 0.50 & 0.50 \\
& & & & \\
Average number of signs and & & & & \\
posters per venue & 0.22 & 0.28 & 2.50 & 3.00 \\
Where & & & & \\
Next to EGMs & 0.11 & 0.11 & 0 & 0 \\
Main gambling area & 0 & 0.03 & 0 & 0 \\
On ATMs & N/A & N/A & 1.75 & 1.75 \\
At change machine/desk * & N/A & N/A & 0.25 & 0.50 \\
Toilets & 0 & 0 & 0.25 & 0.50 \\
Exits & 0.11 & 0.14 & 0.25 & 0.25 \\
\hline
\end{tabular}

* There were no ATMs or change machines in bookmakers

Compared to other venues, and in keeping with the GPSRC, responsible gambling measures were most evident in bookmakers at Phase 1. Of the six different firms in Glasgow City Centre, all members of the Association of British Bookmakers, all had responsible gambling signage, with the exception of one of the smaller independents (Sean Graham). The number of leaflets, brochures, posters and signs displayed, as well as the clarity and positioning of this information, was clearly related to the size of the bookmakers. The largest British bookmaking firms, Ladbrokes and William Hill, with approximately two-thirds of all betting shops in Glasgow City Centre at 
both phases, had responsible gambling signage and leaflets prominently displayed in each shop (average 3 per shop). In contrast, the four smaller bookmaking firms (GalaCoral, Tote, Sean Graham, Betfred) had limited responsible gambling signage at both phases, and in one case no signage at Phase 1 (average 1.6 per shop). In addition, what leaflets and posters were displayed was often obscured from view. There was virtually no increase in the amount of signage displayed at Phase 2 in bookmakers. More importantly, ten of the eleven Ladbrokes shops advertised Category B3 machines throughout their entire stores at Phase 2, essentially dwarfing what responsible gambling signage was evident.

Compliance with GSPRC at Phase 1 (bookmakers) and Gambling Act and LCCP at Phase 2 (arcades and casinos)

One bookmaker had more than four EGMs in their premises at Phase 1, which contravenes the GPSRC but is not illegal given the voluntary nature of the restrictions. At Phase 2 no betting shop contained in excess of four EGMs. Three amusement arcades however had in excess of four Category B3 machines operating simultaneously at Phase 2, in one case as many as eight, which breaches the specifications of the Act stating that only four Category B3 machines can be in operation at any one time. Finally, even though the Gaming Machine Permits Code of Practice (Gambling Commission, 2007c) clearly specifies that all gaming machines are to be located an acceptable distance away from ATMs, so that the individual has to cease gambling in order to do use the ATM, in one casino an ATM was situated directly adjacent to a gaming machine meaning that both could be used simultaneously.

Information on monitoring or controlling gambling behaviour, and self-exclusion Information regarding the availability of measures that are accessible to help an individual monitor or control their gambling, such as self-exclusion or limiting expenditure and the duration of the gambling session, could only be found within leaflets in gambling establishments at either phase. This means that no ambient venue or arcade had information on self-exclusion at Phase 1 , although $75 \%$ of casinos and most betting shops (96\%) had. At Phase 2, no ambient venue, 9\% of arcades and all betting shops and casinos had information pertaining to self-exclusion.

\section{Discussion}

Despite the ubiquity of EGMs in Glasgow City Centre only 55 (4.1\%) displayed responsible gambling signage at Phase 1, although this had increased to 818 (65\%) at Phase 2. On the one hand, this considerable increase in responsible gambling signage could be seen as providing evidence that the new legislation has encouraged compliance among operators, and may be regarded as a positive trend. But on the other hand it is still the case that, with the exception of betting shops, no sector of the gambling industry was able to meet the 'Machine standards' code, the most simplistic responsible gambling measure available. In addition, other infractions were documented with the GPSRC and various elements of the Gambling Act, such as the absence of responsible gambling signage in one betting shop, an ATM situated directly beside machines and having in excess of four Category B3 and B4 machines operational at one time (although the confusion surrounding the number of machines available for use within arcades could have been easily avoided with greater clarity from the Gambling Commission on this matter). These infractions, although relatively minor, nonetheless provide evidence of industry non-compliance and suggest that 
most gambling operators have not embraced the concept of social responsibility as perhaps the government, rather quixotically, would have hoped. The Gambling Commission would be advised to reiterate to gambling operators that infringements of the LCCP are treated seriously; with either a warning from a compliance manager, a non-fixed financial penalty (varies depending on the severity of the infraction) or, in the most severe cases or with repeated offences, the revoking of an operators licence.

The findings also help highlight differential compliance rates across different sectors of the gambling industry. Whereas all bookmakers at Phase 2 fully complied with the Machine standards code and displayed other responsible gambling signage (either leaflets, posters, signs, brochures), most evident in large-chains of betting shops, the same does not hold true for other sectors of the industry. Casinos, like bookmakers, had information relating to responsible gambling in the form of leaflets and posters, etc, in all venues and most EGMs (91\%) displayed responsible gambling signage. Key differences between casinos and bookmakers were evident however. First, even though most EGMs in casinos displayed signage, not one casino had signage on all machines and therefore no casino fully satisfied the Machine standards code. This is a minor problem that is easily rectified given that only 10 of the 111 EGMs in the four casinos was without signage, but it remains difficult to justify the failure of any gambling provider to meet a code that involves nothing more than attaching a sticker to a machine. Second, although the average casino was between two and four times the size of the average betting shop, both contained the same amount of information on responsible gambling. Third, no casino had responsible gambling information (of any kind) next to EGMs or in the main gambling area, as stipulated in the Responsible gambling and help code. Bookmakers, for their part, also had very limited responsible gambling information in the main gambling area, and none in discreet locations such as toilets, but given the much larger size of the gambling area in a casino the absence of any information on gambling responsibly is more disconcerting. The findings clearly demonstrate that arcades are a particularly deviant sector of the gambling industry in respect to meeting social responsibility codes, with very high rates of non-compliance. At Phase 2, no arcade was able to meet the Machine standards code but more importantly, only a meagre 53\% of EGMs in arcades displayed signage. This is staggering for a sector of the gambling industry that provides nothing other than EGMs. Additionally, only one (of twelve) arcades displayed other responsible gambling information such as leaflets and signs.

Despite the inertia displayed by most gambling operators in response to the social responsibility codes assessed, the Gambling Commission must also shoulder blame for the industry's failure to satisfactorily adopt these codes. Although it is clear from the LCCP that implementing responsible gambling signage is now an explicit licensing condition, the use of terms such as 'where relevant', 'all reasonable steps', 'prominent' and 'appropriate to the size of the premises' can be regarded as subjective, open to interpretation and insufficiently assertive to prompt the desired industry response. As a result, not one gambling venue fully satisfied the 'responsible gambling' code, which specified that responsible gambling signage should be accessible near EGMs, ATMs, in the main gambling area and in discreet locations. This highlights that social responsibility is reliant upon adherence by gambling operators and, without explicit policies, the gambling industry can dictate what is meant by 'responsible' and what measures are sufficient to meet this responsibility.

This previous point is exemplified by the 'self-exclusion' code, which states, somewhat vaguely, that operators 'must put in place procedures for self-exclusion'. Self-exclusion remains, if properly employed, an invaluable responsible gambling 
tool (Nowatzki and Williams, 2002; Hing and Mattinson, 2005; Ladouceur et al., 2007). However, this study highlights a problem identified in Victoria (Australia), which is the availability of such schemes (Caraniche Pty Ltd, 2005). No visible signage for self-exclusion was observed in any gambling venue in Glasgow, although mention was made in leaflets. Again, this highlights the failure of the LCCP to specify exactly what operators should do to ensure that information about self-exclusion is actually visible to patrons, and not just hidden away in leaflets (for those venues that actually had leaflets).

The deficiencies and ambiguities in these social responsibility codes may be causing confusion for some gambling operators, who are committed to protecting their customers, and can be easily manipulated by other, disingenuous operators, who are committed to making money whatever the cost to their customers. What is apparent is that imposing minimum standards and, rather optimistically, encouraging gambling operators to employ additional harm minimisation measures, thus demonstrating their commitment to the protection of their patrons and the wider community, appears inadequate. That is not to say that this co-regulatory approach has limited value. On the contrary, it is a favourable option in comparison to selfregulatory approaches, which have been found to be ineffective for a wide range of potentially addictive health risk behaviours such as smoking, alcohol and gambling (Saloojee and Hammond, 2001; Garfield et al., 2003; Casswell, 2004; McMillen \& Toms, 1998). It does, however, rely on industry co-operation, which is often lacking. For example, an evaluation of the perceived awareness and effectiveness of various measures included in a responsible gambling programme (ClubSafe) in New South Wales (Australia), found that although patrons' awareness of responsible gambling signage was high, venues had a tendency to adhere to only mandatory requirements (Hing, 2003). Unregulated measures were considerably less likely to be practised. This echoes the situation in Britain somewhat, except for one significant difference, which is that the ClubSafe programme comprised 33 well-defined responsible gambling measures operating synergistically, and not just a handful of poorly specified measures. As a result, a quarter of problem gamblers in the ClubSafe evaluation reported a reduction in frequency, session length time and expenditure in response to the responsible gambling measures implemented (Hing, 2003). The findings from this study, although observational, suggest that such a reduction would be unlikely in Britain.

The observational findings also bring to light two concerns about signage on EGMs; size of both stickers and wording, and also message content. Mandating the size of stickers, and also of the wording on stickers, is required given the generally small sized, and sometimes microscopic, wording observed in gambling venues. Lessons could be learned from other health-risk behaviours, where an inverse relationship between size and effectiveness of messages has been found. For example, research has found that, in comparison to larger sized responsibility messages concerning alcohol products, smaller sized responsibility messages are less able to attract attention and be recalled, and much less effective (Thomsen and Fulton, 2007). Similarly, the reason underlying the increasingly large health warnings and messages on tobacco products, in accordance with the Framework Convention of Tobacco Control (WHO, 2005), is to reduce tobacco use among present and future generations by informing of the risks. Indeed, large warnings on cigarette packages have been found to be more likely to be noticed and rated as effective by smokers (Hammond et al., 2007; O’Hegarty et al., 2007). 
In relation to message content, the limited literature available suggests that gambling signage should contain information highlighting harms associated with gambling, including potential addictiveness, rectifying erroneous gambling-related cognitions and providing correct odds and probabilities, so that the individual is able to make an informed choice (Blaszczynski et al., 2004; Steenbergh et al., 2004; Schrans et al., 2004; Blaszczynski et al., 2005; Floyd et al., 2006; Monaghan and Blaszczynski, 2007). It is important to highlight that a recent review of the effectiveness of existing responsible gambling research found signage on EGMs to have limited value (Williams et al., 2007). The limited effectiveness of signage, especially for problem gamblers (Hing and Mattinson, 2005), is likely the result of habituation, lack of rotation and size of signage. However, this may be attributable to the failure of the research community to pay greater attention to what signage could prove effective, and for what groups (age, gender, ethnicity, form of gambling). We acknowledge the limitations of signage but believe this area provides potential grounds for optimism for developing strategies to protect gamblers given the reach and frequency of exposure to gambling signage, and also given the promising findings from the tobacco and alcohol literature.

Aside from signage, a variety of other responsible gambling measures have been adopted in other jurisdictions. However, although stakeholders in Australia, New Zealand, the U.S and Canada tend to agree over the general need to reduce the possible harms of gambling, common strategies and principles have not yet been formulated, and so to date, the approach is somewhat piecemeal. Some strategies include, for example, fitting EGMs with 'responsible gambling features' such as timeout and currency limiting devices; locating cash and credit machines away from gaming areas; the training of staff to recognise and deal with signs of problem gambling in customers; and the provision of information centres or kiosks within gaming premises themselves.

Considering some of these strategies in greater detail, responsible gambling features (RGFs) are intended to encourage responsible gambling and limit excessive play. RGFs have been adopted by many sectors of the gambling industry, and are increasingly being mandated by governments (e.g. New South Wales in Australia and Manitoba, Nova Scotia and Québec in Canada). Features include reductions in the size of bets allowed, the speed of games and the intervals between them. Information about time and money spent can also be programmed to appear on machine screens, as well as messages about playing responsibly. However, although a number of jurisdictions have, to varying degrees, introduced a variety of such features, evaluative research has generally been inconclusive as to their overall efficacy (e.g. Blaszczynski, 2001).

In many jurisdictions, various gaming providers, particularly casinos, have begun to make use of information kiosks on their premises. These provide advice on responsible gambling, and can make referrals to specialist agencies if they feel a player's behaviour has become out of control. For example, the Crown Casino Customer Support Centre in Melbourne is a facility inside the casino where players can obtain information and referrals as well as professional counselling and access to a self-exclusion programme (Crown Casino, 2004). Similar programmes exist in Canada, and some are complemented by specialist counsellors who provide general training sessions for customers on how gambling works and how to play safely. The introduction of similar services in casinos in the UK would undoubtedly benefit patrons but unfortunately the progress made elsewhere in terms of responsible 
gambling has outpaced the limited progress made in the UK, although the same is equally true for the provision of suitable treatment for those with gambling problems.

\section{Limitations}

The present study is limited to observational research and did not aim to garner information from patrons of gambling establishments regarding awareness and perceived effectiveness of current signage. Such research, ideally employing a longitudinal design, would complement the present research and allow for a more comprehensive understanding of the potential value of responsible gambling measures. It should also be noted that the collection of the data within one month of the introduction of the Gambling Act may also constitute a limitation of this exercise. It is certainly possible that the implementation of responsible gambling measures may require longer than this to come into full effect. Additionally, our study focused on EGMs, as opposed to other forms of gambling, which may be considered a limitation. However, as a minimum of $70 \%$ of problem gambling has been consistently contributed to this form of gambling (Gambling Research Australia, 2007), it was the logical choice of investigation. Furthermore, as we covered a range of gambling venues, and therefore a number of different forms of gambling, this increases the generalisability of the findings.

\section{Conclusions}

That most gambling establishments in Glasgow (Scotland) fail to provide adequate information about problem gambling suggests the ethos of social responsibility putatively ingrained in the Gambling Act is being largely ignored. As many gambling operators, particularly smaller independents, may not wish to implement strategies aimed at harm minimisation when their goal is to increase profit and market share, the Gambling Commission must act accordingly. They have the power to review and modify existing regulatory controls and, if required, impose more stringent and explicit licensing conditions that operators have to meet in regards the provision of responsible gambling. Indeed, this preliminary investigation suggests that the Commission should keep existing controls and industry practices under close scrutiny and if future research, as and when it emerges, provides further evidence of noncompliance and failure to embrace the responsibility that accompanies operating a gambling venue, then tightening licensing conditions may be the appropriate course of action.

\section{No conflict of interest declared}

\section{References}

Abbott, M. 2006. 'Do EGMs and problem gambling go together like a horse and carriage’, Gambling Research, 18, pp. 7-38.

Blaszczynski, A. 2001. Harm minimization strategies in gambling: An overview of international initiatives and interventions. Report prepared for Australian Gaming Council.

Blaszczynski, A., Ladouceur, R. and Shaffer, H.J. 2004. 'A science-based framework for responsible gaming: The Reno Model', Journal of Gambling Studies, 20, pp. 30117. 
Blaszczynski, A., Ladouceur, R., Nower, L. and Shaffer, H., 2005. Informed choice and gambling: Principles for consumer protection. Melbourne, Australia: Australian Gaming Council.

British Medical Association 2007. Gambling addiction and its treatment within the NHS: A guide for healthcare professionals. London: BMA.

Caraniche Pty Ltd 2005. Evaluation of electronic gaming machine harm minimisation measures in Victoria. Final report prepared for Victorian Gambling Research Panel.

Casswell, S. 2004. 'Alcohol brands in young peoples' everyday lives: New developments in marketing', Alcohol and Alcoholism, 39, pp. 471-6.

Cox, B.J., Enns, M.W. and Michaud, V. 2004. 'Comparisons between the South Oaks Gambling Screen and a DSM-IV-based interview in a community survey of problem gambling', Canadian Journal of Psychiatry, 49, pp. 258-63.

Crown Casino 2004. Responsible Gaming. Retrieved 1 August 2008 from www.crownltd.com.au/home.asp

Department for Culture, Media and Sport 2007. Gaming Machines. Retrieved 15 November 2007 from www.culture.gov.uk/Reference_library/Press_notices/archive_2007/dcmsmpgm_07.ht $\underline{\mathrm{m}}$

Floyd, K., Whelan, J.P. and Meyers, A.W. 2006. 'Use of warning messages to modify gambling beliefs and behaviour in a laboratory investigation', Psychology of Addictive Behaviours, 20, pp. 69-74.

Gambling Commission 2007a. Licence Conditions and Codes of Practice. Retrieved 17 November 2007 from

www.gamblingcommission.gov.uk/UploadDocs/publications/Document/LCCP\%20Ju ne\%202007.pdf

Gambling Commission 2007b. Machine standards Category B3, B4, C and D (Legacy machines). Retrieved 17 November 2007 from

www.gamblingcommission.gov.uk/UploadDocs/Contents/Documents/Machine\%20St andards\%20B3,\%20B4,\%20C\%20and\%20D\%20(Legacy\%20machines).pdf

Gambling Commission 2007c. Gambling machine permits codes of practice:

Responses. Retrieved 17 November from

www.gamblingcommission.gov.uk/UploadDocs/Contents/Documents/Gaming\%20M achine\%20Permits\%20Code\%20of\%20Practice\%20Responses.pdf

Gambling Research Australia (2007). Identifying problem gamblers in gambling venues. Gambling Research Australia. Retrieved 1 August 2008 from http://www.gamblingresearch.org.au/CA256DB1001771FB/page/GRA+Research+Re ports-Identifying+problem+gamblers+in+gambling+venues?OpenDocument \&1=35GRA+Research+Reports $\sim$ 2=0Identifying+problem+gamblers+in+gambling+venues $\sim \& 3=\sim$ 
Gambling Review Body (2001). Gambling Review Report. Norwich: HMSO.

Garfield, C.F., Chung, P.J. and Rathouz, P.J. 2003. 'Alcohol advertising in magazines and adolescent readership', The Journal of the American Medical Association, 289, pp. 2424-9.

Götestam, K.G. and Johansson, A. 2003. 'Characteristics of gambling and problematic gambling in the Norwegian context', Addictive Behaviours, 28, pp. 18997.

Hammond, D., Fong, G.T., Borland R., Cummings, K.M., McNeill, A. and Driezen, P. 2007. 'Text and graphic warnings on cigarette packages: Findings from the International Tobacco Control Four Country study', American Journal of Preventive Medicine, 32, pp. 202-9.

Hing, N. 2003. An assessment of member awareness, perceived adequacy, and perceived effectiveness of responsible gambling strategies in Sydney clubs. Sydney: Centre for Gambling Research.

Hing, N. and Mattinson, A. 2005. 'Evaluation of the NSW ClubSafe responsible gambling program: Opportunities and challenges for New Zealand clubs', eCommunity - International Journal of Mental Health and Addiction, 3, pp. 61-9.

Hodgins, D.C. and el-Guebaly, N. 2004. 'Retrospective and prospective reports of precipitants to relapse in pathological gambling', Journal of Consulting and Clinical Psychology, 71, pp. 71-80.

Ladouceur, R., Sylvain, C. and Gosselin, P. 2007. 'Self-exclusion program: A longitudinal evaluation study’, Journal of Gambling Studies, 23, pp. 85-94.

Light, R. 2007. 'The Gambling Act 2005: Regulatory containment and market control', Modern Law Review, 70, pp. 626-53.

MacCallum, F. and Blaszczynski, A. 2003. 'Pathological gambling and suicidality: An analysis of severity and lethality', Suicide and Life-Threatening Behaviours, 33, pp. 88-96.

McMillen, J. and Toms, M. 1998. Report of the Responsible Gambling Trial Program for NSW Clubs. Australian Institute for Gambling Research, UWS.

Miers, D. 2007. 'Another U-turn: Great Britain’s casino questions and other gambling issues’, Gaming Law Review, 11, pp. 699-713.

Monaghan, S. and Blaszczynski, A. 2007. 'Recall of electronic gaming machine signs: A static versus a dynamic mode of presentation', Journal of Gambling Issues, 20. Retrieved 1 February 2008 from www.camh.net/egambling/issue20/08monaghan.htm 
Moodie, C. 2008. 'Student gambling, erroneous cognitions and awareness of treatment in Scotland', Journal of Gambling Issues, 21. Retrieved 22 August 2008 from www.camh.net/egambling/issue21/03moodie.htm

Moodie, C. and Finnigan, F. 2006. 'Prevalence and correlates of youth gambling in Scotland', Addiction Research and Theory, 14, pp. 365-85.

MORI/IGRU 2006. Under 16s and the National Lottery. London: National Lottery Commission.

Nowatzki, N.R. and Williams, R.J. 2002. 'Casino self-exclusion programs: A review of the issues', International Gambling Studies, 2, pp. 3-25.

O’Hegarty, M., Pederson, L.L., Nelson, D., Wortley, P. and Yenokyan, G. 2007. 'Young adults' perceptions of cigarette warning labels in the United States and Canada', Preventing Chronic Disease, 4, pp. A27.

Orford, J. 2005. 'Disabling the public interest: Gambling strategies and policies for Britain’, Addiction, 100, pp. 1219-25.

Pietrzak, R.H. and Petry, N.M. 2005. 'Antisocial personality disorder is associated with increased severity of gambling, medical, drug, and psychiatric problems among treatment-seeking pathological gamblers', Addiction, 100, pp. 1183-93.

Reith, G. 2007. 'Gambling and the contradictions of consumption', American Behavioural Scientist, 51, pp. 33-55.

Saloojee, Y. and Hammond, R. 2001. Fatal deception: the Tobacco Industry's “new” global standards for tobacco marketing. Report prepared for the World Health Organisation.

Schrans, T., Schellinck, T. and Grace, J. 2004. Nova Scotia VLT self exclusion program process test: Final report. Halifax, Nova Scotia: Focal Research.

Steenbergh, T.A., Whelan, J.P., Meyers, A., May, R.K. and Floyd, K. 2004. 'Impact of warning and brief intervention messages on knowledge of gambling risk, irrational beliefs and behaviour', International Gambling Studies, 4, pp. 3-16.

Thomsen, S.R. and Fulton, K. 2007. 'Adolescents' attention to responsibility messages in magazine alcohol advertisements: An eye-tracking approach', Journal of Adolescence, 41, pp. 27-34.

Williams, R.J., West, B.L. and Simpson, I.R. 2007. Prevention of problem gambling: A comprehensive review of the evidence. Report prepared for the Ontario Problem Gambling Research Centre, Guelph, Onatrio, Canada.

World Health Organisation 2005. WHO Framework Convention on Tobacco Control. Geneva: World Health Organisation. 